\title{
Analysis of Research Methodology for Human Sciences
}

\author{
Kasomo Daniel
}

Department of Religion Theology and Philosophy Maseno University in Kenya

\begin{abstract}
This paper aims at laying this ghost of Religion as a Science to rest by establishing the link between Physical sciences and Human sciences using scientific methodology. We intend to put a case for the Human sciences by systematically arguing out the fact that Human sciences are truly sciences and that the very methodology employed by the physical sciences are the ones used in social sciences. We shall also establish where they differ especially as regards intention. It is also our hope that we explicate the scientific character of religious knowledge and to establish the third way in which we can study both physical and social sciences. Part One deals with the nature of science which will help us to know exactly what we mean by science. We shall also examine the relationship that exists between physical sciences and social sciences. Part Two deals with the scientific character of religious knowledge and how it fits within the general understanding of science. In Part Three, we trace the development of phenomenology of religion as the method for studying religion and how phenomenology is a science just like any other science. Finally, we shall apply the knowledge so gained to the study of religion and how religion is studied. In the final analysis, we want to find out whether religious studies can truly be called "Religious science".
\end{abstract}

Keywords Human, Religion, Science, Studies

\section{Introduction}

Science has always had an edge over what is referred to as humanities in the scholarly world. In schools and Universities, science subjects are considered to be a matter of the "tough guys" while arts are for those who fail to make it in science. Sometimes it is referred to as a man's subject because it tough and so it has acquired a certain importance and credibility at the expense of other disciplines especially humanities.

\section{Research Methodology for Human Science}

In general terms research means to carry out a diligent inquiry or a critical examination of a given phenomenon. It implies exhaustive study, investigation or experimentation following some logical sequence. Research involves a continuous search for knowledge and understanding of the world around us. Mouly (1990) defines research as a process of arriving at effective solutions to problems through semantic collection, analysis and interpretation of data.

Methodology on the other hand comes from two words, $\mu \varepsilon \tau \alpha$ ' $\delta o \varsigma$ and $\lambda \mathrm{o} \gamma \mathrm{O} \varsigma$ which literally means "the study or discipline of the way of doing things." Method is a special

\footnotetext{
* Corresponding author:

dkasomocounselling@yahoo.com (Kasomo Daniel)

Published online at http://journal.sapub.org/ijpbs

Copyright (C) 2012 Scientific \& Academic Publishing. All Rights Reserved
}

form of procedure especially in any branch of mental activity. It refers to orderliness, regular habits, orderly arrangement of ideas, a scheme of classification. Methodology, then is a science of method, a body of methods used in a particular branch of activity.

In the words of Van Kaam (1983), a methodology can be defined as: A directive set of systematic approaches to a specific object of knowledge that increasingly discloses the scientifically relevant facets of that formal object as well as the dynamic interactions of these unfolding facets with one another and with their conditions and consequences.

These "dynamic interactions" is what Lonergan calls "the normative pattern of recurrent and related operations yielding cumulative and progressive results. To him, there is a method where there are distinct operations, where each operation is related to the others, where the set of relations forms a pattern, where the pattern is described as the right way of doing the job, where operations are in accord with the pattern may be repeated indefinitely and where the fruits of such repetitions are cumulative and progressive. This summarises for our purpose, what we refer to as Research Methodology.

\section{Human Science.}

It is also important to know what we refer to when we talk of Human Sciences. The rise of science in general is a crucial event in our history. It has enabled people to shape life and the world in a whole new fashion. Science and technology is changing humanity especially in our new Millennium of globalisation facilitated by advanced computerisation. 
Among the sciences, those called human are concerned with the typically human aspects of our unfolding lives (Van Kaam 1987:1ff). There has always been a tendency among Scientists especially nature Scientists to distinguish between Natural Sciences and Human Sciences. However, Human sciences have also come to be accepted as a "science" in that they employ a critical methodology that entails systematic, logical, coherent, consistent validation to study human realities. The human sciences today have slowly gained acceptance by scholars because of their effectiveness in addressing social and religious issues that affect individuals and groups of people. Their difference with natural sciences in regard to method and purpose will be examined in due course.

\section{Nature of Science.}

According to Nachamias and Nachamias (1992), science is "all knowledge collected by means of the scientific methodology." The scientific method of acquiring knowledge is a systematic process of investigating a research problem following some principles. From this definition, we can discover that research and science are both concerned with the discovery of new facts or truths.

A question has always been poised as to whether we can study religion scientifically. This discussion leads us to the discussion of the different approaches in research. Mugenda (1999), pins down the debate to "Qualitative versus quantitative approaches in research" (Mugenda, 1999:197ff). The scientific method, often referred to as the quantitative approach, has traditionally been considered as the conventional mode of inquiry in both research an evaluation. This mode of inquiry follows several logical and distinct steps, namely:

i) identifying and stating a research problem within a theoretical framework,

ii) formulating the objectives of the study,

iii) formulating hypotheses from theoretical propositions,

iv) defining and operationalising the variables of the study the variables of the study and specifying procedures that will be used in collecting data,

v) collecting data from a sample randomly selected from a defined population,

vi) testing the null hypotheses using appropriate statistical tests,

vii) making appropriate conclusions, inferences or generalisations to the population based on the outcomes of statistical tests.

(Mugenda, 1999:198).Human scientists contend that the scientific method is not the only approach used in research and evaluation. There are other approaches equally useful in building a body of knowledge. Unfortunately, many people have been conditioned to thinking that the quantitative approach is the only legitimate mode of inquiry. It is common knowledge today that many researchers and evaluators are often under pressure from funding agents and decision makers to use the quantitative approach in research and evaluation simply because this approach yields numbers, charts and tables which are more convincing.

However, another mode of inquiry is now receiving a great deal of attention, namely the qualitative approach. Qualitative research or evaluation is an umbrella term for various types of interpretative modes of inquiry commonly used in social sciences. Whilst the quantitative and qualitative approaches are similar in sequence and method, the way the researchers put the various components together in each approach makes for differences in both process and the finished product. Mugenda notes that the fundamental and effective differences between the two methods are philosophical assumptions within which each mode of inquiry operates. In the words of Strasser (1985), natural sciences deal with explanation and human sciences deal with understanding. There is then a shift in paradigm, a shift in understanding.

\section{Human Science as a Science.}

Mill asked a question concerning the nature of a methodology for the human sciences: "Should human science adopt the methodology of physical sciences?"

Mill took the affirmative side while Dilthey took the negative side. Todate, Mill's side ahs carried the day and their position has been adopted as a standard methodology for the human sciences by University departments, textbooks and journals.

The proponents of this view have developed and refined their position. The most significant refinement occurred in the 1920s when Russell's new logic was added to the empirical tradition. Polkinghorne (1983) calls this refinement "the received view". The received view supplies the methodological underpinnings for most of the contemporary behavioural and social sciences committed to Mill's thesis.

The development of philosophy of science can be organised into the five phases proposed by Frederick Suppe.

Phase 1: (1920) Description of observations.

During this phase, it was proposed that science should limit its statements to descriptions of regularities that held in observations.

Phase 2: (1940) Universal theoretical statements.

In this phase, philosophy of science expanded to include theoretical statements that referred to non-observable entities and that construction of an axiom-based network of universal statements.

Phase 3: (1960) Critique of logical positivism.

This phase consisted of the critique of assumptions of logical positivism.

Phase 4: Analysis of history.

This proposed alternative systems for science based on an analysis of the history of science.

Phase 5: Contemporary phase.

This phase is a reconstruction of science based on pragmatic reason an acceptance of the influence of historical 
conditions on scientific inquiry.

\section{The Scientific Character of Religious Knowledge.}

It is often said that a subject is scientific in so far as it in measure it conforms to scientific procedures and in the measure they do not, they are something less than scientific. Ross (1949) remarked of Aristotle:

Throughout the whole of his works we find him taking the view that all other sciences than the mathematical have the name of science only by courtesy, since they are occupied with matters in which contigency plays a part." (Ross, 1949:51ff).

So too today the English word, science, means natural science. One descends a rung or more the ladder when one speaks of behavioural or human sciences. The matter becomes more acute when it comes to religion. Some simply include it not in the list of sciences but of academic disciplines. That is the reason why Lonergan suggests the third way. He insists that it must be found and, even though it is difficult and laborious, that price must be paid for the under looked disciplines. He appeals to the successful sciences to form a preliminary notion of method. He then goes behind the procedures of the natural sciences to something more general and fundamental, namely, the procedures of the human mind. In the procedures of the human mind, he discerns a transcendental method, which he calls the third way. Lastly, he indicates the relevance of transcendental method in the formulation of other, more special methods appropriate to particular fields.

According to Lonergan, method is either an art or a science, ie, something that can be learnt by doing or through scientific procedures. The artistic person and the scientist have something in common: they are subjects, that is, they are people doing something. They share the human mind. Method to Lonergan then, is not a set of rules to be followed. Rather, it is a framework of collaborative creativity. Method inculcates a spirit of inquiry. It insists on accurate observation that leads to discoveries, which are formulated into hypotheses. The hypotheses have implications or generalisations. Lonergan's method is then, a pattern - the right way of getting a job done. Inquiry transforms mere experiencing into scrutiny which is described and hence leads to discovery.

He goes on to outline the basic patterns of the operations of the human mind. He says that all these operations are transitive, that is, they have an object. All these operations intend, for example, if you see or hear you become present to that which you see or hear. These operations are operations of the subject. One operates consciously: the subject must raise that which he is present to, to a conscious level. There is then a psychological dimension. There is introspection, that is, the process of objectifying the content of consciousness. He then distinguishes the different levels of consciousness and intentionality, namely:

i. Empirical level in which we sense, perceive, speak, imagine, move, etc. The activity here is sensing. Hence be attentive.

ii. Intellectual level in which we inquire, understand and express. The human activity here is inquiring. Hence be intelligent.

iii.Rational level in which we reflect, marshal evidence, pass judgement. The human activity here is judgement. Hence be reasonable.

iv. Responsible level in which we consider the possible courses of action, evaluate, decide and carry out decisions. The human activity here is acting. Hence be responsible.

In this sense, he concludes that everyone knows and observes transcendental method. Everyone does so, precisely in the measure that he is attentive, intelligent, reasonable, responsible. By implication then, all artists and scientists are using the transcendental method.

Religious knowledge, therefore, has a scientific character. The question we ask is then: How can we study religion scientifically? Cox (1992) answers this in his book, Expressing the Sacred: An Introduction to the Phenomenology of Religion.

\section{Phenomenology of Religion.}

The phenomenological method in the study of religion emerged out of a larger movement which developed in the $19^{\text {th }}$ Century which emphasised the scientific study of religion. Phenomenology accepted, along with other scientific approaches, the need to describe religion objectively. In this sense, it reacted against all forms of theological compartmentalisation, the explanation of religious phenomena exclusively in terms of disciplines other than religion, for example, sociology, psychology or anthropology (scientific reductionism), the evolutionary theories concerning the origins of religion and the projectionist explanations or religion.

Scientific Reductionism. Reductionism is a form of narrowness characterised by compartmentalisation. It means to explain religious phenomena (hence reducing it) in terms of methods employed and the conclusions reached by disciplines other than religion. The social sciences have shown a particular tendency towards reductionism. Platvoet (1990:20) contends that this has occurred because "the primary field of the social sciences is not the religions themselves." The psychologist, for example, tends to interpret religious phenomena in terms of emotional needs and may thus ignore the religious meaning of myths, rituals, sacred practitioners and other phenomena for believers.

The phenomenologist argues that explanations of religion in terms of other disciplines distort the phenomena from the point of view of the believer by forcing religious data to conform to the presuppositions of a particular discipline rather than allowing the phenomena to speak for themselves. Richard Plantinga (1989):177) explains that it is the believer's sole right to testify about their religion. This will act to correct the imbalances which result from discussions of religion exclusively from the "outside". 
Harrold Turner (1981:14) argues that this tendency to reduce religious experience to social, scientific explanations ahs been particularly prevalent in Africa. These earlier distortions of African religions will not be overcome if the social and behavioural sciences view African religions exclusively as objects of study, because the impression will be that African religions are no more than the social and psychological phenomena rather than essentially religions and worthy to be professed as the faith of persons. The tendency by social scientists to do this explains the first fundamental reason why the phenomenological study of religion was developed.

Evolutionary Theories concerning the origin of religion.

Explanations from other disciplines often search for the causes of religion in human societies. Historically, these were explained in terms borrowed from the theory of biological evolution of Darwin. With the acceptance of this theory as a scientific fact, scholars began to look for parallel developments occurring in cultures, societies and religions. It was assumed that the universal religious tendency in humanity originated in a primitive form and gradually evolved into more advanced expressions. Man's religion, like his body, was thought to have evolved from inferior to more advanced forms.

These scholars included: Auguste Comte (1789 - 1857), James Frazer (1854-1941) and Tailor (1832-1917). Their theories all share preconceived ideas about development. They begin with evolutionary assumptions and impose them on religious data. Phenomenologists accused them of interpreting the phenomena before actually observing them.

In reaction to this the phenomenologists adopted the procedure of epoche to avoid this error, that is, suspension of judgement and allow data of religious experience speak for themselves.

Projectionist Theories.These assume that religion has developed out of some human need which has been enlarged and projected on to an ultimate being. Hence their hypothesis is: God is created in the image of man rather than man being created in the image of God.

The Projectionists include: Ludwig Feurbach (1804-1872), Sigmund Freud (1860-1939) and Emile Durkheim (1858-1917).

Theological Reductionism.In theological reductionism, every religion is evaluated according to the criteria established by one. According to Cox, religions which emphasise that their beliefs are revealed by God often interpret every other religion in the light of that claim.

Phenomenological objection is not against theology but against theological interpretations of religion in the light of certain truth claims. It fails to describe and appreciate other religious experience and therefore, blocks understanding. Religion is not the same thing as theology.

\subsection{Other Ways of Studying Religion.}

Other disciplines provide what Harold Turner (1981) calls the "milieu" into which religion is interwoven. What they cannot do is to explain fully the meaning of religion because their object of concern is not the religious phenomena themselves but the application of their own disciplines to the religious phenomena. Phenomenology is the study "of what is interwoven into the milieu". The proper subject matter of phenomenology is the religious phenomena. Hence, phenomenology affirms religions as a discipline sui generis, as a classification of its own.

Phenomenology affirms religious traditions remain loyal to what they conceive to be God. It does not defend nor attack the belief in God. The phenomenologist, in search of understanding, empathises with that loyalty without making any judgement.

\section{Application to Religion.}

Let us now move from reflection on the ways human beings order their lives and the ways that religions assist them in doing so to the way scholars study the ordering process they call religion. Nancy (1998) in talking about the ways in which we order our lives uses the terms "culture" "nature" and "nature." She points out that these terms are complementary frames, reciprocal mental constructs which help us to talk about our life in the world and therefore, they are useful in studying religion.

"Nature" is what is given while "culture" is what human beings create, a pattern of living. Nature includes land, water, trees, animals, people in their biological nature, etc. while culture includes the technical processes for obtaining food and shelter, conventions for living, etc. Nature and culture are complementary. Religion is part of culture which belongs specifically to ideology. Each culture is a pattern for living, created within a context of constraints and possibilities. It is transmitted from generation to generation, and the pattern changes over time.

Cultures propose different understandings of what is meant to be human, and they educate the potential human being so that it may approach the cultural ideal of personhood. According to Ring (1998), that area of culture which we refer to as religion is employed in inculcating such understandings. Religion then, provides narratives and paradigmatic rituals to encourage the development of the person and the community. Though word and ritual, religion transmits its vision of true humanity from generation to generation. This vision is certainly continuously challenged and modified. Hence, there is a need of openness and dialogue in reflecting on religion.

\section{The Study of Religion.}

The term "religion" is often used to mean gaining access to what is considered life-giving. Scholars use the term when they study people's ideas and practices concerning whatever is considered to be ultimately life-giving. Human beings also link themselves to what they consider as most empowering. 
Jews, Christians and Muslims may call this God, Malenesians may be referring to the ancestors and land of the spirits, Buddhists may value Nirvana and the Taoists nature. When scholars study all these quests for life in its fullness, they do so under the rubric of religion. Other disciplines may be helpful to the study of these insights.

The modern study of religion grew out of the Enlightenment, a philosophic movement which questioned traditional authority and put emphasis on the use of reason. The movement stimulated people to think for themselves and question any knowledge that was passed to them from generation to generation. There came a need to use the scientific method, not tradition as a way of understanding. The Enlightenment encouraged scholars to be more critical in their study of religion, to make use of the scientific and historical tools of investigation. The study of religion went beyond the confines of religious institutions to the larger academy.

\section{Defining Religion}

In order to think about religion in a systematic way, it is important to try to define religion. In the words of Ring (p61), definitions set boundaries for what we are examining and the attempt to define obliges us to clarify our ideas. Of course definitions are not always value-free; they tell us a lot about the person trying to make them especially their interests and orientation.

In almost all the definitions of religion that have been made, two characteristics usually feature and which we shall have a working definition of religion, namely: Religion is the awareness of relationship to or participation in the fundamental power of life which is expressed in symbols. This definition allows that the practitioner of religion may believe in God or spirits or the influence of ancestors but does not require that he or she do so. This definition like that of Smith J.Z. and Ring N. focuses on religion as a system of symbols, or a system of beliefs and practices, embedded in human experience. Others will focus on religion as experience of the transcendent especially those with theological orientation and those who wholeheartedly profess faith in a transcendental reality.

\section{Symbolic Expression.}

Most people in Religious Studies see that an awareness of and openness to symbolic language is basic to the study of religion. Human beings communicate with symbols, that is, with words, gestures and objects that evoke and stand for other things. Symbols carry meaning. They help human beings to interpret their experience.

A symbol is something that stands for something else. We can distinguish between representational symbols and presentational symbols. Representational symbols point or stand for something but they do nor necessarily participate in the realities for which they stand. Presentational symbols are necessarily connected to what they symbolise. They present the other through its own qualities. Religious symbols are presentational.

The meaning of symbols is determined by the contexts in which they are located. Very often they are part of rituals or part of religious narratives. Religious symbols, such as the Eucharist, point to the fundamental power of life, to the sacred. They draw us beyond our everyday lives into the power and mystery of life. In other words, symbols suggest an ultimate order and meaning which we are encouraged to create in the world.

Conclusively, we have seen how religion is an area of human experience. We have suggested that religion is a symbolic process which enables us to make connections to the world beyond ourselves, to think about and get in touch with the fundamental power of life, to bring order and meaning to the time and space in which we live. People who study religion may or may not be religiously inclined themselves. Those who are religious and who study religion want to better understand the nature and practice of religion. Those who are not religious, nevertheless, are fascinated with the role that religion has played and continues to play in this world.

\section{Conclusions}

There has always been a conflict in the use of the term science. Knowledge is got from everyday experience which comes from traditions of religions and ideological belief systems. These are contained in tenets such as myths, folktales, art, ceremonies, superstitions, etc.

We also have scientific knowledge which is a critical appraisal of popular opinion. Science picks from traditions and subjects them to critical appraisal distinguishing falsehood, naivety from truth. From here, we have moved to knowledge which is more exact and not just to take things at face value. Science then becomes the critico-methodological investigation which entails systematic, logical, coherent, consistent validation of truth. The tools it uses are concepts. We have established that this is easy and understandable for natural sciences because we are talking of observable, measurable and quantifiable realities.

When, however, we come to Human sciences, for example, religion, which also seeks to study human realities scientifically, the story changes. This is where the conflict begins. We have tried to establish a relationship between physical sciences and human sciences and how human sciences can truly be called sciences. Several authors have been invoked to reiterate the fact that religious knowledge too has a scientific character.

Eventually we have come to the conclusion that, both the scientist and the artist make use of the third way: the transcendental method as explained at length by Lonergan. As regards the method, both of them use the same methods. The only difference comes in intentionality. Science seeks to explain phenomena while human sciences seek to understand it. 
In the light of the aforementioned, our paper can truly be called Religious Science.

\section{REFERENCES}

[1] Cox J., 1992, Expressing the Sacred: An Introduction to the Phenomenology of Religion, Harare: University of Zimbabwe Publication.

[2] Frazer, J.G.,1923, The Golden Bough, London:Macmillan.

[3] Kuhn, T.S.,1962, The Structure of Scientific Revolution, New York: State University Press.

[4] Kasomo D.,2006, Research methods in Education and Humanities, Njoro: Egerton University Press.

[5] Kasomo D.,2010, Introduction to Research Methods, Germany: LAP Academic Publishing.

[6] Kasomo D.,2010, Research Methods for College and University Students, Germany: LAP Academic Publishing.

[7] Kasomo D.,2010, Research Methodology Made Simple for University and Colleges, Germany: LAP Academic Publishing.

[8] Kasomo D. ,2010, Research Methods Made Simple for University Students, Germany: LAP Academic Publishing.

[9] Kasomo D.,2010, Qualitative and Quantitative Research Methods Made Simple, Germany: LAP Academic Publish- ing.

[10] Luijpen, A.W.,1969, A First Introduction to Existential Phenomenology, Pittsburg: DUP.

[11] Macquarrie, J.,and Robinson E.S., 1962, Being and Time, London: SCM.

[12] Mugenda, O., and Mugenda, A.,1999, Research Methods, Nairobi: ACTS.

[13] Ogula, P.,1998, A Handbook on Educational Research, Nairobi: New Kemit Teache Education Series.

[14] Otto, R.,1932, The Idea of the Holy, London: Oxford.

[15] Platvoet, J.G.,1990, Akan Traditional Religion, Zimbabwe: Harare University Press.

[16] Polkinghorne, D.,1983, Methodology for Human Sciences, New York: State University of New York Press.

[17] Strasser, S.,1985, Understanding and Explanation: Basic Ideas concerning the Humanity of Human Sciences, Pittsburg: DUP.

[18] Turner,H.,(1990), "The way forward in the religious study of African primal religions", Journal of Religion in Africa, XII, $1-15$.

[19] Ring,N.,1998, Introduction to the Study of Religion, New York: Orbis Books.

[20] Van Kaam, A.,1987, Scientific Formation, Vol I \& IV,New York: Crossroads.

[21] Viladesau,R., 994, World Religions, New York: Paulist Press. 